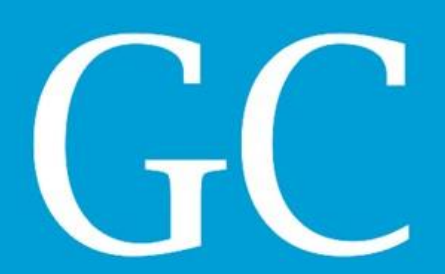

ISSN 2318-8472

v. 06, n. 43,2018

Revista Nacional de

Gerenciamento de Cidades

National Journal of Cities Management

\title{
(Re)ativação do espaço público através da intervenção urbana: coletivo Raumlabor e o Cantiere Barca
}

(Re)activation of the public space through urban intervention: Raumlabor collective and the Cantiere Barca

(Re) activación del espacio público a través de la intervención urbana: el colectivo Raumlabor y el Cantiere Barca

Samara Ferreira Crispim

Mestranda em Arquitetura e Urbanismo, UFU, Brasil samara.crispim@hotmail.com

Adriano Tomitão Canas Professor Doutor, UFU, Brasil adrcanas@ufu.br

Juscelino Humberto Cunha Machado Júnior

Professor Doutor, UFU, Brasil juscelinomachado@icloud.com 


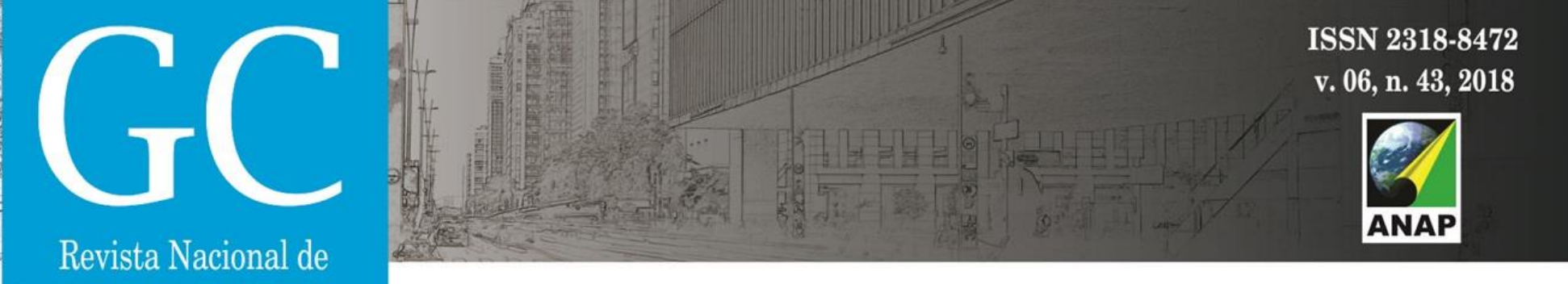

Gerenciamento de Cidades

\section{INTRODUÇÃO À DISCUSSÃO}

A cidade, composta por ruas, edifícios, jardins, praças, avenidas e comércios, é considerada como "um objeto espacial que ocupa um lugar e uma situação" (LEFEBVRE apud ARAUJO, 2012, p.134) enquanto o "urbano é a simultaneidade, a reunião, é uma forma social que se afirma" (LEFEBVRE apud ARAUJO, 2012, p.134). Tal contexto pode ser compreendido por uma pluralidade de ações diluídas em práticas cotidianas, individuais e coletivas, formadas por inúmeros elementos que comumente passam despercebidos e nos são automáticos como o simples ato de caminhar, habitar, falar, circular, trabalhar e até mesmo de nos relacionar.

São estas atividades, muitas vezes despretensiosas, que contribuem para que a cidade seja o lugar da diversidade, numa condição multifuncional e adaptável que abriga inúmeras e distintas atividades capazes de induzir o indivíduo a diferentes percepções acerca do espaço público, compreendido como campo que retrata o cotidiano dos indivíduos que, por sua vez, se reconhecem em grupos constituídos, segundo Halbwachs (2006), por meio de vivências de acordo com suas preferências e convívios sociais estabelecidos com outros sujeitos ou com uma comunidade afetiva.

Para Lefebvre (2001), o cotidiano acontece sem que o indivíduo o perceba com clareza, efetivando-se mediante simples ações, muitas vezes diárias. Certeau (2000), por sua vez, identifica o cotidiano como o espaço propício à inventividade e à resistência, para que os indivíduos construam sua própria história frente as questões postas pela sociedade e pelas situações vividas, em uma cultura plural e heterogênea que quebra com a uniformização do dia-a-dia a partir das pequenas práticas individuais, sendo "natural que se perceba microdiferenças onde tantos outros só veem obediência e uniformização" (CERTEAU, 2000, p.19).

\footnotetext{
Se há uma produção da cidade, e das relações sociais na cidade, é uma produção e reprodução de seres humanos por seres humanos, mais do que uma produção de objetos. A cidade tem uma história; ela é a obra de uma história, isto é, de pessoas e de grupos bem determinados que realizam essa obra nas condições históricas. (LEFEBVRE, 2001, p. 46)
}

Lefebvre (2001) considera que a cidade pode ser requalificada por meio de distintos processos de significações, como as intervenções urbanas, criando identidades e identificações espaciais, assumindo-se como ponte que conecta as pessoas aos espaços públicos, estimulando a emergência de coletividades efêmeras frente as pré-existências, transformando o espaço em local de encontro propício a comunicação que estimula as trocas e a sociabilidade.

A cidade responde a conteúdos sociais ao longo do tempo histórico moldando sua identidade, estabelecida a partir de um processo que está inserido no plano da memória coletiva e das relações sociais por meio do deslocamento dos passantes e da forma com que os indivíduos criam vínculos entre si, reconhecendo-se em grupos, considerando os contextos espaciais que os envolvem. 


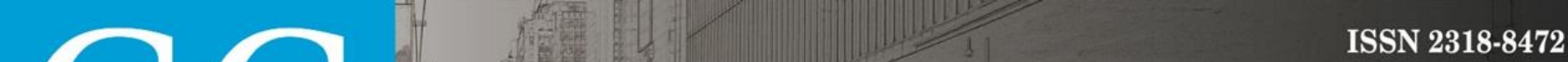

Revista Nacional de Gerenciamento de Cidades

Os espaços, segundo Halbwachs (2006), desempenham o papel de detentores das formas de vida e dos valores dos grupos, concretizados sob moldes relativamente estáveis de acordo com a imagem e semelhança dos indivíduos.

Segundo o autor (2006), a memória coletiva não se relaciona apenas à experiência inicializada e concluída no passado, mas a algo que se mantém vivo e apresenta múltiplas condições baseando-se no ponto de vista inerente aos grupos, na medida em que cada um deles cultiva um conjunto particular de lembranças, vivificando assim as ações e pensamentos dos indivíduos na atualidade, fatores essenciais para formar uma comunidade de sentimentos que constroem a noção de identidade enquanto grupo social, em que "as identidades não estão nos indivíduos, mas emergem na interação entre os indivíduos agindo em práticas discursivas particulares nas quais estão posicionados" (MOITA LOPES, 1998, p. 8).

Essa noção de identidade social é construída a partir da subjetividade dos sujeitos, considerando os grupos em que estão inseridos, os contextos em que vivem e os valores que os cercam, firmando uma espécie de diálogo constante entre seu interior, suas vivências e percepções exteriores, afirmando a ideia de que a "identidade é formada na 'interação' entre o eu e a sociedade" (HALL, 2006, p. 11).

Assim, os objetos que compõem os espaços e as circunstâncias intrínsecas à eles envolvem os grupos fazendo com que seus integrantes consigam compreendê-los e interpretá-los como um conjunto de recordações comuns, possibilitando então a formação de identidades e memórias que cumprem a importante função social de colaborar para a manutenção e coesão dos espaços e dos grupos, estimulando seus membros a produzirem e manterem o sentimento de identidade.

Para que haja identidade, os grupos em que os indivíduos se reconhecem cultivam uma espécie de voz e consciência coletiva, promovendo consenso e convergência num processo colaborativo em que as memórias estimulam um senso de conexão por meio dos eventos e dos espaços.

Huyssen (2000) discute questões referentes ao dinamismo dos eventos efêmeros, em que a condição efêmera é paradoxal frente ao caráter permanente das marcas que estes eventos geram, construindo uma espécie de nova monumentalidade que se contrapõe à imobilidade dos monumentos históricos como símbolos das grandezas dos grupos. Ele aponta essas relações por meio de um paradoxo no qual:

\footnotetext{
o monumentalismo do espaço construído e as tendências monumentais em qualquer outro meio continuam a ser difamadas, mas a noção do monumento como memorial ou evento comemorativo público vem conhecendo um retorno triunfante. (HUYSSEN, 2000, p.42)
}

Huyssen (2000) considera que a fluidez dos eventos efêmeros surte mais efeito quando relacionada à vitalidade da cidade do que a vasta quantidade de monumentos permanentes construídos nos espaços públicos na contemporaneidade, resultando num novo conceito de 


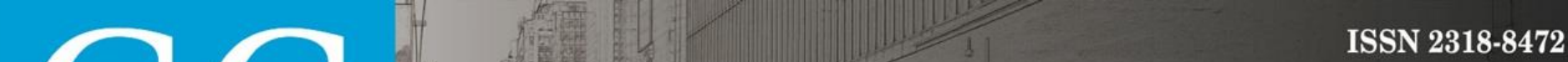

Revista Nacional de Gerenciamento de Cidades

monumentalidade que vive "com a impermanência e sem a destruição, que é fundamentalmente enformada pelo espírito modernista de uma epifania fugaz e transitória, mas que nem por isso é menos memorável ou monumental" (HUYSSEN, 2000, p. 62).

O evento efêmero, enquanto intervenção urbana, é capaz de resgatar as relações entre os indivíduos enquanto grupo social e sua percepção frente aos espaços da cidade, englobando desde práticas artísticas até o urbanismo tático, que reflete acerca do engajamento artístico em problematizar a cidade e se aproxima mais do domínio do design e da arquitetura do que das artes plásticas em si, acrescentando questões lógicas e funcionais aos processos críticos, desenvolvendo ações e projetos a fim de solucionar problemas que a área urbanística têm enfrentado na contemporaneidade.

É justamente neste cenário contemporâneo que emergem as ações de urbanismo tático. Ligadas à apropriação de espaços públicos críticos como resposta autônoma que independe do Estado, este tipo de evento preenche algumas lacunas na cidade em que as ações do poder público não se efetivam.

Engajadas em promover a ativação ou a reativação dos espaços urbanos, as intervenções táticas transformam os lugares ao propor outros usos que envolvem uma série de processos colaborativos e acontecem a partir de manifestações particulares que visam a elaboração de novos contextos urbanos funcionais, com baixo custo e curto intervalo de tempo, de caráter efêmero ou permanente.

Frente à estas ações de participação cívica, o governo começa a notar o potencial destes eventos como resposta temporária aos problemas urbanos na cidade. Fato que pode desencadear novos dilemas, tendo em vista que esta apropriação mais sutil do espaço público pode inibir algumas das responsabilidades do Estado às cidades.

O poder público começa então a convidar profissionais da área de design e arquitetura para desenvolver e guiar ações de intervenção tática, promovendo atividades culturais na cidade como resposta às necessidades sociais, adiando, em parte, problemas estruturais e de planejamento urbano. (GADANHO, 2001)

Em contraposição, as intervenções táticas temporárias dão ênfase ao problema e suscitam o estudo de novas soluções às deficiências de planejamento urbano das cidades. Com isso, podemos observar um equilíbrio ao refletir que, por mais que estes eventos efêmeros não sejam a solução ideal aos impasses mencionados, eles dão luz às comunidades desfavorecidas ou excluídas, que provavelmente não teriam tido qualquer tipo de atenção sem estas ações e que, simultaneamente, despertam o seu empoderamento ao enfatizar que é possível transformar o contexto em que vivem se responderem ativamente à ele.

Desse modo, as ações de urbanismo tático lançam o importante debate acerca dos problemas de planejamento urbano das cidades, tornando-os mais visíveis para que se possa perspectivar um plano de ações mais amplo e eficaz, agindo como uma espécie de alerta que caminha em busca de uma solução ideal e conta com a participação da população. 


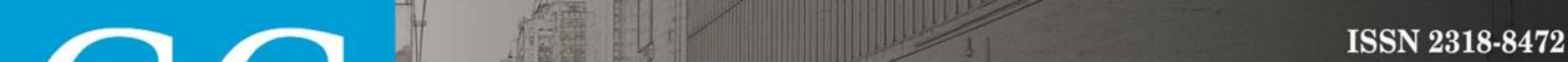

Revista Nacional de Gerenciamento de Cidades

É possível notar também uma preocupação das ações provenientes do urbanismo tático em restaurar laços ao construir lugares que promovem o reestabelecimento de vínculos sociais como resposta aos paradigmas individualistas do contexto contemporâneo marcado "pelo curto prazo, pela falta de compromisso mútuo originada no estresse da rapidez e pelas relações superficiais entre indivíduos" (FONTES, 2013, p. 12).

Segundo Pedro Gadanho (2001), estas questões associadas ao urbanismo tático apresentam indícios de uma mudança que nos levam à versão complexa do conceito de utopia, numa espécie de microutopia que se manifesta em efêmeros espaços de resistência, a nível das pequenas ações que tornam a cidade um objeto apropriável para seus habitantes, mesmo que de maneira simbólica e pragmática.

Desse modo, a ideia de utopia sobre as ações que resultam do diálogo na cidade se relacionam à possibilidade da sua existência, como microutopia possível, e encontra resposta frente à condição caótica das cidades contemporâneas que segue a lógica do urbanismo tático, de preservar desejos utópicos no mundo globalizado, especificamente distópico, de precariedade e instabilidade.

Dentre as recorrentes práticas do urbanismo tático pode-se citar a criação de bibliotecas, cinemas ao ar livre, hortas comunitárias, entre outros; além da conversão de terrenos baldios, estacionamentos ou calçadas em lugares vivificados que mudam as percepções dos grupos frente às áreas que antes eram estigmatizadas.

Assim como no âmbito da arte, algumas das ações de urbanismo tático são pensadas especificadamente para determinados lugares, numa espécie de site de instalação, mas que também podem ser replicadas a partir de sua ideia central que adquire novas identidades a partir dos distintos locais em que se inserem.

\section{OBJETIVO E MÉTODO DE PESQUISA}

Esta pesquisa objetiva analisar o modo como os eventos efêmeros, enquanto intervenção urbana e urbanismo tático, podem contribuir para a requalificação das cidades na contemporaneidade, ressignificando os espaços públicos e, por consequência, a memória coletiva e a identidade social dos grupos em prol de uma sociedade menos individualista, mais humana e consciente. Com um caráter predominantemente qualitativo, na primeira etapa desta pesquisa foi desenvolvida uma revisão bibliográfica coerente acerca do tema central e suas transversalidades através da análise de publicações, livros, periódicos, sites, monografias e teses nacionais e estrangeiras. Composto o alicerce bibliográfico desta discussão, foi desenvolvida a segunda etapa da pesquisa, em que o resultado consiste na análise de caso que coloca a prova as questões levantadas neste trabalho por meio de fotografias, documentos e relatos encontrados em documentos e sites com credibilidade comprovada. 


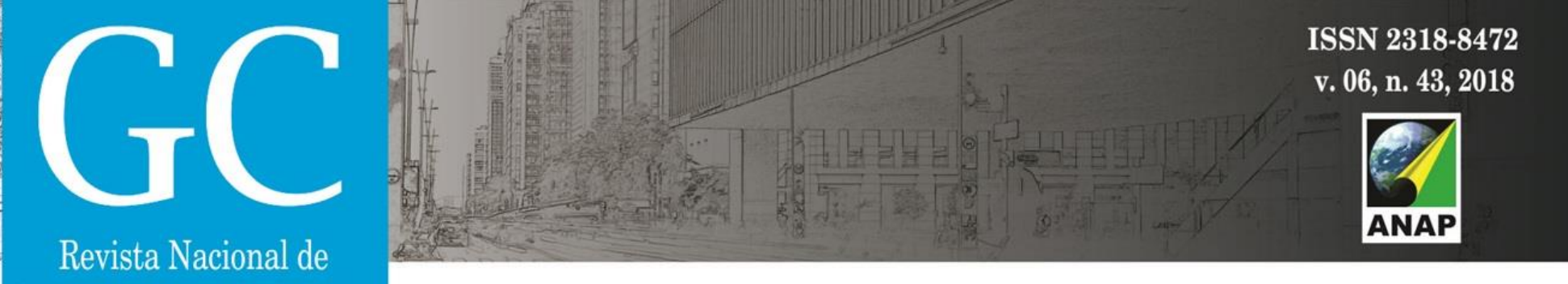

Gerenciamento de Cidades

\section{ANÁLISE DE CASO: coletivo Raumlabor e o Cantiere Barca}

Partindo do pressuposto que a cidade é um lugar de interação e coexistência, os designers e arquitetos que desenvolvem ações de urbanismo tático acreditam que seus projetos devem ser concebidos de forma ativa, fazendo do ambiente uma espécie de campo para a experimentação, sugerindo a intervenção urbana enquanto processo colaborativo que caminha na contramão daqueles individuais, em que os profissionais

abandonaram as posições românticas, introspectivas ou contemplativas. Como disse Hal Foster, eles [os designers, artistas e arquitetos] acolheram "o regresso do real" nas suas práticas, aceitando trocar a postura autônoma por uma forma semiautônoma. Com esta transição, adotaram práticas consideradas essenciais para abordar uma das condições da distopia: "[...] a distribuição de conhecimento, a recuperação da memória, o acesso a informação livre, a produção de pensamento crítico, a construção da esperança e a criação de resistência." (GADANHO, 2013, p. 201).

Recorrendo ao urbanismo tático, o coletivo Raumlabor se apropria, de modo efêmero, dos espaços na intenção de suscitar um processo marcado pelo estímulo ao reconhecimento e a apropriação dos grupos frente ao urbano, auxiliando no progresso e no desenvolvimento do local em que se interviu, desencadeando importantes fatores que prezam pela vivacidade dos espaços e pela sociabilidade.

Raumlabor é um coletivo alemão composto por arquitetos que trabalham relacionando arte e design e atuam no desenvolvimento de uma vasta gama de projetos de intervenções urbanas, desde oficinas de arte pública até o urbanismo tático de construção colaborativa, propondo projetos especializados em desenvolver estratégias de ativação e planejamento dinâmico, reinventando e ressignificando espaços públicos, assumindo "a responsabilidade de testar microutopias que jogam com uma distopia intrusiva" (GADANHO, 2013, p. 201).

Os modos de organização, produção e criação do Raumlabor investem em formas de existência relativamente independentes dos mercados da arte, do design e da arquitetura, assegurando uma consciência crítica nestes campos, preservando "um nível mínimo de relevância num sistema social cada vez mais materialista e desequilibrado" (GADANHO, 2013, p. 201), apontando em direção ao seus caráteres públicos, promovendo intervenções urbanas que correspondem à conceitos de colaboração, participação e ação que compartilham valores e tarefas.

Em nossos projetos, formamos equipes personalizadas de especialistas interdisciplinares. Os moradores da cidade também são especialistas. Ninguém sabe melhor das situações locais do que aqueles que lidam com elas diariamente. Assim, podemos obter informações valiosas sobre a história, medos, desejos, necessidades existenciais, bem como déficits, que existem como uma rede invisivel sobre cada situação espacial. Forjamos alianças ativas entre atores locais e especialistas externos. Assim, descobrimos novas áreas de ação e abrimos novos campos de 


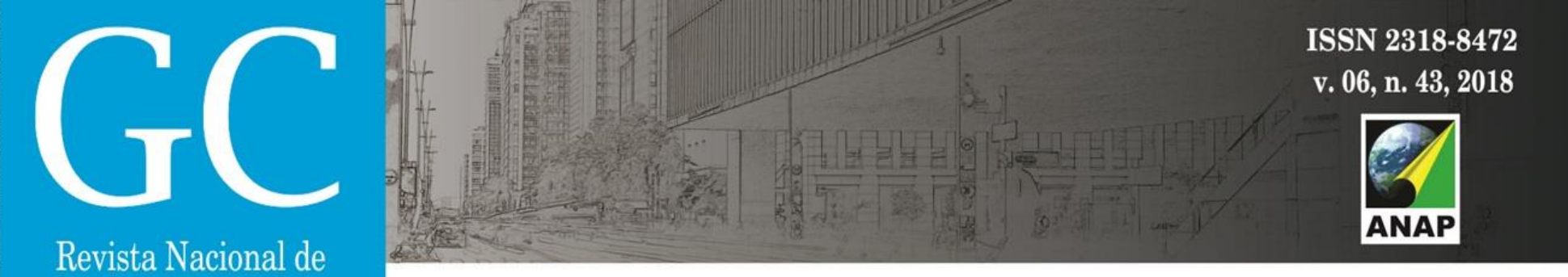

Gerenciamento de Cidades

experimentação, cujas possibilidades testamos e examinamos coletivamente. (RAUMLABORBERLIN, tradução nossa ${ }^{1}$ )

Como estratégia de ativação dos lugares da cidade, seguindo os moldes do urbanismo tático, o coletivo explora novos espaços a fim de descobrir aqueles que estão esquecidos ou a mercê de efeitos degradantes para, em seguida, pensar a melhor maneira de conduzir a intervenção.

Em sua essência, eles iniciam "processos que dão aos atores a oportunidade de conhecer, entender e usar a cidade e suas dinâmicas, bem como suas possibilidades" (RAUMLABORBERLIN, tradução nossa ${ }^{2}$ ), para que os espaços públicos sejam ocupados e os efeitos de suas ações sejam permanentes.

Com a curadoria de Francesca Comisso, Luisa Perlo, Maurizio Cilli, Giulia Majolino e Alessandra Giannandrea, o Coletivo pôde desenvolver um projeto de urbanismo tático promovendo uma série de workshops com base colaborativa no Barca em 2011. (RAUMLABORBERLIN)

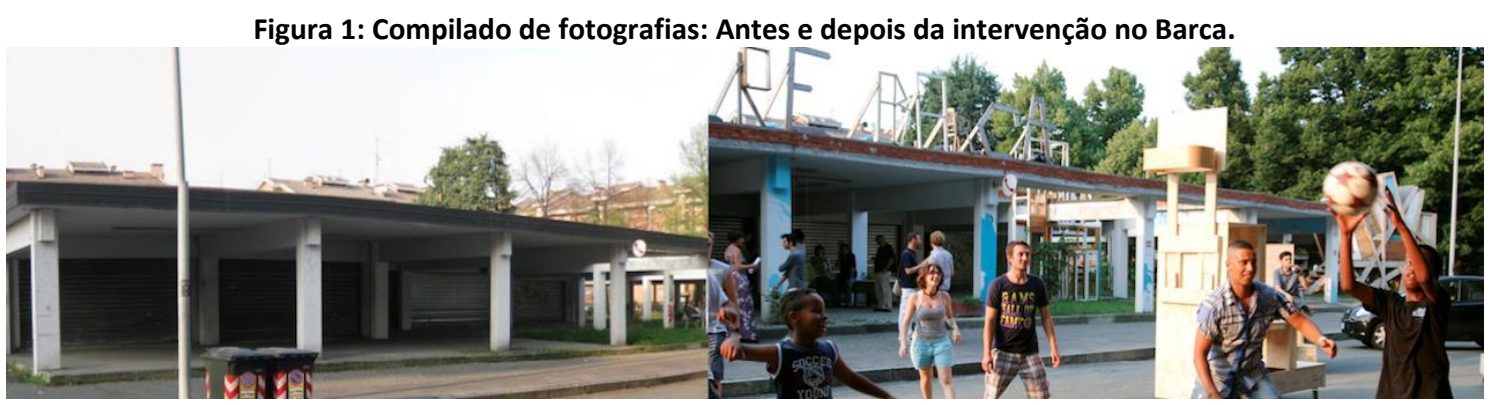

Fonte: Social Making Economies. http://socialmakingeconomies.studiosuperfluo.com/it/tesi/il-progetto-cantierebarca-parte-1/

Barca é um bairro da cidade de Turim, na Itália, composto por propriedades residenciais que foram construídas na década de 70 para abrigar pessoas que buscavam emprego na indústria automobilística; Atualmente, é um subúrbio com poucas possibilidades que acolhe refugiados em situações difíceis.

O bairro, localizado numa área periférica da cidade, é um exemplo típico de planejamento urbano do modernismo tardio: composto por edifícios residenciais de habitação social, duas escolas, um par de parques infantis e um pequeno centro com um galpão que deveria ser sede de um supermercado, mas nunca o fora. (BRAVO, 2018)

A primeira oficina promovida pelo coletivo produziu um letreiro feito com pedaços de mobília descartada que soletrava o nome do projeto: Cantiere Barca. Elas foram instaladas no telhado

\footnotetext{
${ }^{1}$ Texto original: "For our projects, we form tailored teams of interdisciplinary experts. City residents are also specialists. No one knows better in each respective situation than those who have to deal with the places on a day to day basis. Thus we can gain valuable information about the history, fears, desires, existential needs, as well as deficits, that exists like an invisible network over every spatial situation. We forge active alliances between local actors and external experts. Thus we discover new areas of action and open new fields of experimentation, whose possibilities we test and examine collectively." (RAUMLABORBERLIN)

${ }^{2}$ Texto original: "We do not solve problems, rather we initiate processes that give actors the opportunity to know, understand and use the city and its dynamics, as well as its possibilities." (RAUMLABORBERLIN)
} 


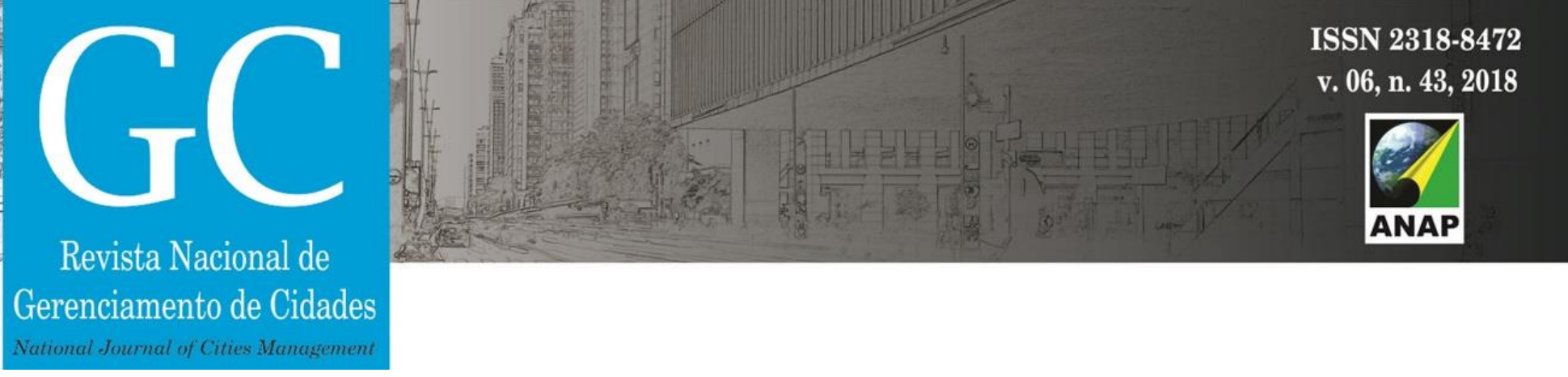

do galpão abandonado, símbolo da inércia do bairro, como forma de atrair a atenção para a intervenção.

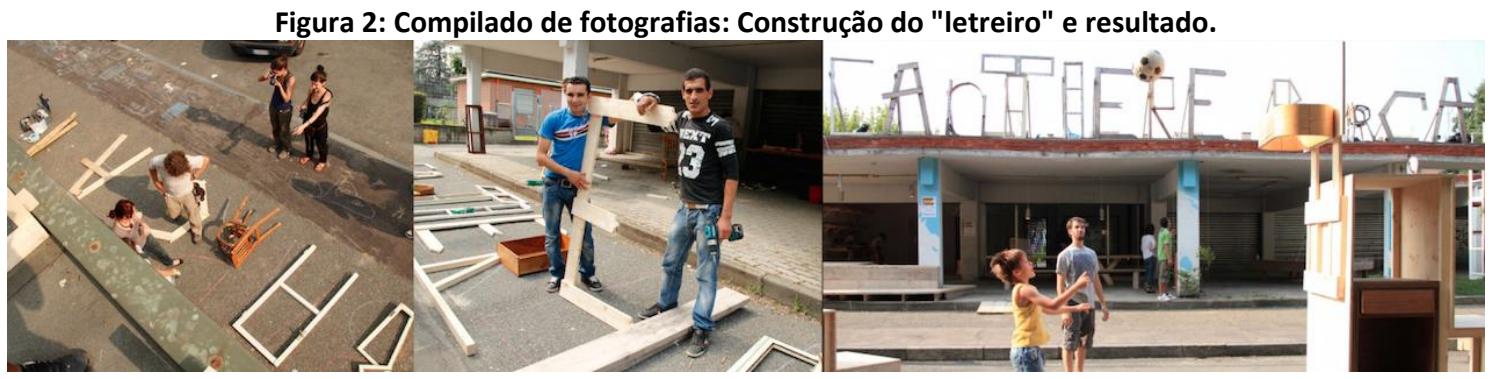

Fonte: Raumlaborberlin e Les Nouveaux Commanditaires http://raumlabor.net/cantiere-barca e http://www.nouveauxcommanditaires.eu/fr/news/15/cantiere-barca-is-back!

A partir desta primeira ação, todos os esforços foram dedicados a transformar o prédio vazio em um centro social vivificado e autogerido, que acabou se tornando uma espécie de marco monumental do bairro.

Os participantes dos workshops discutiram, guiados pelos curadores do projeto, quais seriam as ações mais viáveis e importantes que precisavam tomar pra ressignificar o espaço público do bairro, compartilhando ideias esboçadas em papel, discutindo-as até serem acordadas por todos.

Figura 3: Compilado de fotografias: Parte do processo de criação, reunião e execução do projeto.

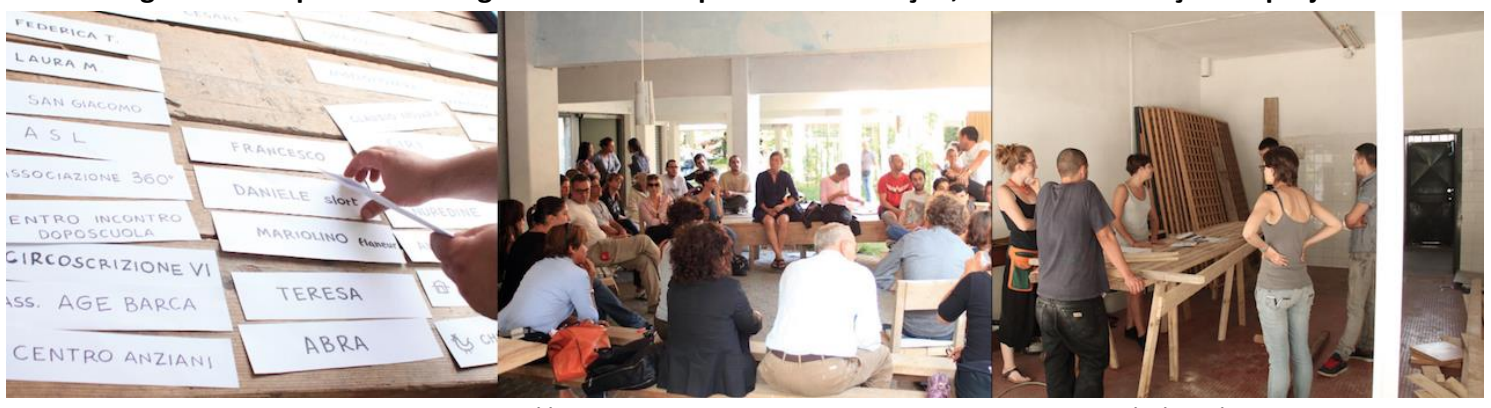

Fonte: Social Making Economies http://socialmakingeconomies.studiosuperfluo.com/it/tesi/il-progetto-cantierebarca-parte-1

A escolha pela utilização de madeira reutilizada para a construção das instalações foi fruto de uma consciência ecológica discutida em conjunto, que também era resposta frente aos limites orçamentários do projeto, e que acabou agregando ainda mais valor à produção, traduzindo-se em um tipo de construção não-convencional.

Neste projeto, o Raumlabor não visava apenas capacitar as pessoas por meio das oficinas, ensinando-lhes o ofício da carpintaria mas, tinha como objetivo central fortalecer os laços sociais no Barca, demonstrando aos grupos que, a partir da metodologia de trabalho colaborativo, eles poderiam fazer com que o impacto proveniente da intervenção prosperasse 


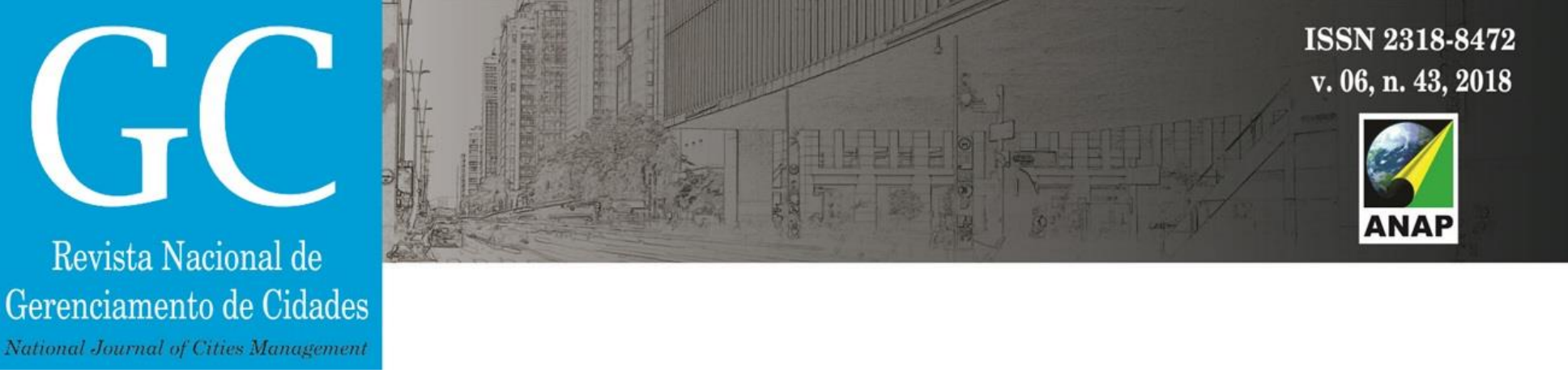

ao longo do tempo, numa condição contrária à efemeridade do evento, mudando permanentemente a realidade e a identidade da comunidade local.

O coletivo foi o responsável por guiar os moradores em relação ao autogerenciamento dos espaços do bairro e à autoconstrução, ensinando também sobre o uso das tecnologias para a concepção das peças, envolvendo-os numa experiência completa e enraizada nas percepções do espaço e da identidade dos grupos a fim de ativar os processos de cidadania e ocupação que potencializaram o patrimônio material e imaterial do bairro.

Como resultado deste processo colaborativo e à medida em que as oficinas prosseguiam, desenvolviam-se diversos tipos de dispositivos urbanos como plataformas para realizar atividades sociais, esportivas e de lazer, que estimulavam a sociabilidade entre idosos, jovens e crianças do bairro e incluíam cestas de basquete, traves de futebol, palco para palestras e shows, estruturas para apoiar jardins suspensos, bancos e instalações lúdicas.

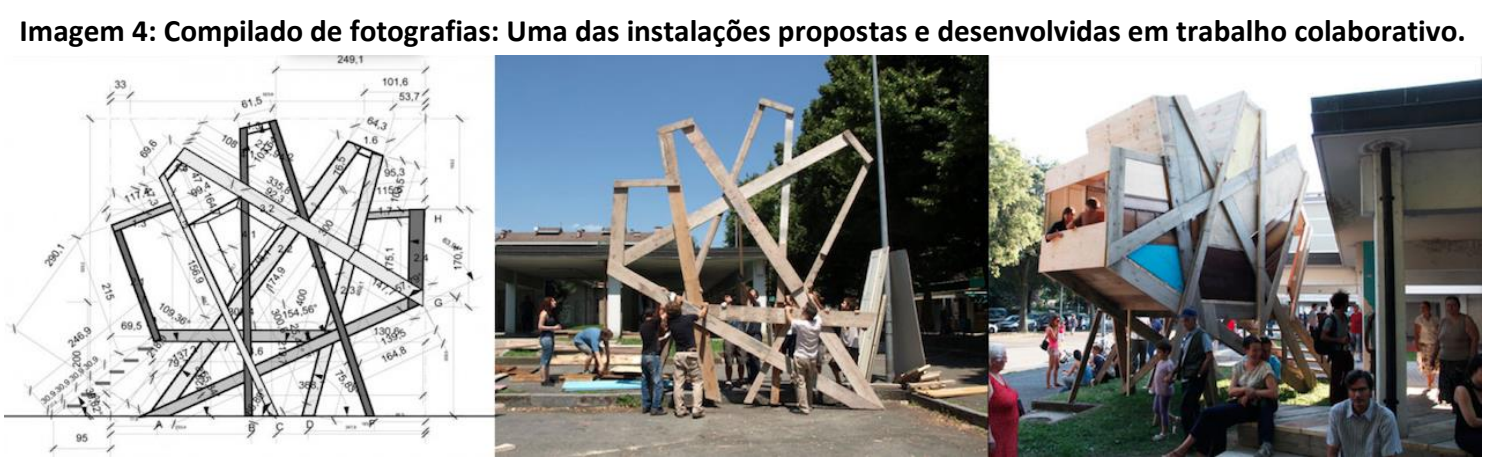

Fonte: Raumlaborberlin http://raumlabor.net/cantiere-barca

O projeto colaborativo e o trabalho compartilhado agiram como incentivos estimulantes a criatividade dos grupos que habitavam o bairro, independente de sua faixa etária, despertando o sentimento de pertencimento e amabilidade urbana.

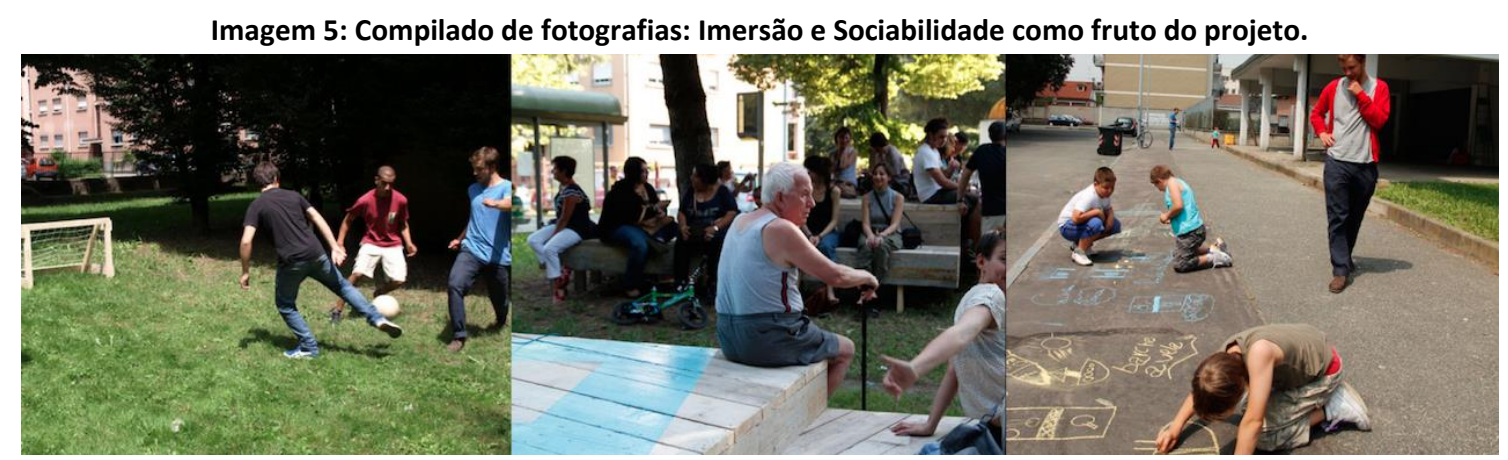

Fonte: Raumlaborberlin http://raumlabor.net/cantiere-barca

A requalificação urbana proposta foi bem sucedida por relacionar-se diretamente com a preocupação que o coletivo teve com aspectos para além da estética da obra, considerando 


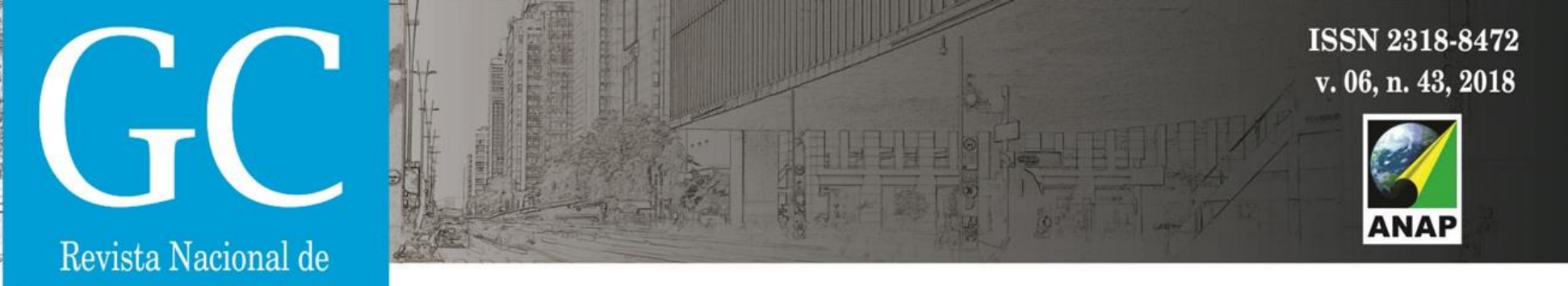

Gerenciamento de Cidades

também contextos econômicos, ambientais e sociais que se relacionam ao conceito de qualidade de vida.

Ao longo do processo de construção dos dispositivos e mobiliários urbanos, os jovens aprenderam passo a passo como lidar com as ferramentas de carpintaria e deram ao bairro, em conjunto com o Raumlabor, uma nova identidade social em que os grupos se reconheciam como parte integrante da cidade.

$\mathrm{O}$ ato de construir e projetar em colaboração foi a principal ferramenta dentro do processo de apropriação dos espaços do bairro, em que os grupos que o habitavam conseguiram perceber que as respostas e soluções contra o descaso e a degradação do espaço público surgiram, principalmente, a partir de suas percepções e atitudes.

O trabalho de urbanismo tático desenvolvido atribuiu ao espaço uma nova identidade social, como já mencionado, fazendo do galpão ocupado um novo marco monumental do bairro, que continua vivificado, autônomo e autogestionado.

\section{CONCLUSÃO}

Sabemos que ao circular pelas ruas, os indivíduos são afetados de modo racional, sensitivo e instintivo, sobrepondo memórias de eventos já ocorridos. Esta relação, mediada pelo corpo e pela mente, cria sensações e associações do indivíduo aos espaços da cidade.

A intervenção urbana como evento efêmero, paradoxalmente à sua transitoriedade, interfere nos espaços e na vida coletiva dos grupos gerando sobre a cidade impactos que costumam ser duradouros, assumindo-se como ferramenta de reestruturação, ressignificação e sociabilidade. As inter-relações que as práticas artísticas estabelecem com a cidade se estendem e se ramificam, associando-se ao contexto da cultura, da realidade social, do dinamismo contemporâneo e principalmente da identidade.

Estes aspectos fazem com que seja possível entender o modo como a dinâmica das inúmeras realidades sociais aparecem impressas nos projetos interventivos nas cidades, como os contextos específicos são refletidos nas obras dos autores através do conceito que eles assumem e, principalmente, da forma resultante destas intervenções, que apresentam um caráter inseparável da experiência sensível e da vivência coletiva para além das salas dos museus e galerias de arte.

O caráter de ação do coletivo Raumlabor, acrescido de sua forma de organização independente, oportuniza conexões inesperadas pela cocriação e pela justaposição, redesenhando outras dimensões possíveis na realidade dos grupos, ressaltando a preocupação com a alteridade em que o processo constitutivo aberto característico de suas produções ocasionam uma explosão de singularidades que se distanciam progressivamente da concepção moderna de um caminho único como forma de resistência aos poderes dominantes.

As intervenções urbanas em seu caráter totalizante, efêmero, fragmentado e transformador, representam mais do que um jogo criativo entre o artista, o designer, o arquiteto e a cidade, 
transmitindo efeitos além de sua composição meramente visual, sonora ou performática, tornando-se ponte para vivências/experiências individuais e coletivas, aptas a remodelar os contextos das cidades contemporâneas por meio da apropriação e da interferência, impulsionando transformações sociais, econômicas e culturais que dispõem do poder de modificar as percepções dos indivíduos frente aos espaços.

Assim, ao adquirir uma centralidade visível capaz de capturar temas relevantes da contemporaneidade, as intervenções urbanas resultam na inclusão de visões e comportamentos exigidos pelas práticas das inter-relações entre os campos da arte, do design e da arquitetura, mostrando-se pertinentes no instante em que os designers buscam novas abordagens para equacionar os desafios da atualidade e passam a construir a cidade a partir das ações interventivas, no sentido de promover uma transformação em sua paisagem rígida, incentivando novos comportamentos capazes de estimular a experiência sensível, a sociabilidade e o intercâmbio cultural, assim como novas memórias e identidades.

\section{REFERÊNCIAS}

ARAÚJO, James A. Sobre a cidade e o urbano em Henri Léfèbvre in GEOUSP - Espaço e Tempo, no31, p.133 - 142. São Paulo: Universidade de São Paulo, 2012.

ARGAN, Giulio Carlo. História da arte como história da cidade. São Paulo: Martins Fontes, 1993.

BRAVO, David. Cantiere Barca in Public Space. Acesso em 20/07/2018. Disponível em < https://www.publicspace.org/works/-/project/h109-cantiere-barca>

BUTTINELLI, Gianluca; FORTINO, Francesco. Il progetto Cantiere Barca in Social Making economies. Acesso em 16/07/2018. Disponível em < http://socialmakingeconomies.studiosuperfluo.com/it/tesi/il-progetto-cantiere-barcaparte-1>

CERTEAU, Michel. A invenção do cotidiano: artes do fazer. 5a ed., Petrópolis: Editora Vozes, 2000.

GADANHO, Pedro. Utopia/Distopia: breve história de uma dualidade incómoda. In: Utopia/Dystopia: A paradigma Shift in Art and Architecture. Milan: Mousse Publishing. 2013, p. 197-204.

HALBWACHS, Maurice. A memória coletiva. Tradução de Beatriz. Sidou. 2ª ed. São Paulo: Centauro, 2006.

HALL, S. A Identidade cultural na pós-modernidade. 11. ed. Rio de Janeiro: DP\&A, 2006.

HUYSSEN, Andreas. Seduzidos pela memória: Arquitetura, monumentos, mídia. Rio de Janeiro: Aeroplano, 2000.

LEFEBVRE, Henri. O Direito à cidade. São Paulo: Centauro, 2001.

MOITA LOPES, Luiz Paulo da. Read, read, read oitava série. São Paulo: Ática, 1998.

RAUMLABORBERLIN. Acesso em 09/07/2018. Disponível em <http://raumlabor.net> 